\title{
A predictive protocol to obtain maximum water-free oil production rate for perforated vertical wells
}

\author{
James O. Adeleye ${ }^{1} \cdot$ Olugbenga Olamigoke $^{2} \oplus \cdot$ Oluseun T. Mumuni $^{3}$
}

Received: 3 July 2020 / Accepted: 25 September 2020 / Published online: 13 October 2020

(c) The Author(s) 2020

\begin{abstract}
Producing an oilfield in a cost-effective way depends on how long water production could be delayed in the reservoir. Many flow mechanisms, correlations, and methods to calculate maximum water-free oil production rate have been published, However, those methods have generally failed to not consider the skin effect which affects the flow into the wellbore. In this paper, the semi-analytical perforation skin model as presented by Karakas and Tariq is incorporated into the Meyer and Garder correlation for critical oil rate from a perforated vertical well interval to obtain the maximum water-free oil production rate and optimal perforation parameters. The resulting coupled computational model is used to determine the sensitivity of the maximum water-free oil production rate to wellbore perforation parameters. Whilst an increase in perforation length and decrease in spacing between perforation increase the critical flow rate, an increase in perforation radius did not translate to higher productivity. The optimal perforation angles are $45^{\circ}$ and $60^{\circ}$, however, for the data used in this work the maximum water-free oil rate of $23.2 \mathrm{std} / \mathrm{d}$ was obtained at $45^{\circ}$ of phasing angle, 1 in of spacing between perforation, 0.36 in of perforation radius and 48 in of perforation length. Thus, the perforation strategy can be optimized prior to drilling and completion operations to improve productivity using the computational model presented in this work.
\end{abstract}

Keywords Computational model $\cdot$ Perforation strategy $\cdot$ Maximum water-free oil production rate $\cdot$ Perforation parameters . Water breakthrough

\section{Introduction}

An increase in the cost of production operations, environmental problems, reduction in depletion mechanism efficiency and processing of the produced water are major challenges to production and reservoir engineers. Oil or gas reservoirs will produce with increasing water cuts especially from zones with active underlying aquifers that tend to elevate the water-oil contact in the vicinity of the completion interval. This necessitates the determination of the maximum waterfree oil production rate that a completed well can deliver. The flow mechanisms, correlations and methods to calculate this critical rate have been developed for wells completed

Olugbenga Olamigoke

oolamigoke@unilag.edu.ng

Society of Petroleum Engineers, Lagos, Nigeria

2 Department of Chemical and Petroleum Engineering, Faculty of Engineering, University of Lagos, Lagos, Nigeria

3 Department of Petroleum Resources, Lagos, Nigeria in a continuous pay zone with oil-water contact or gas-oil contact or both (Meyer and Garder 1954; Chierici et al. 1964; Høyland et al. 1989; Menouar and Hakim 1995; Zhang et al. 2011; Tabatabaei et al. 2012). Correlations have also been developed to predict the water breakthrough time and time for a well to produce above its critical rate (Papatzacos et al. 1989; Yang and Wattenbarger 1991). These common analytical formulas have been developed to calculate the critical rate without considering the effect of perforation or using the perforation interval of zero, which is practically impossible. Meanwhile, perforation has been reported to be one of the factors that affect both coning (Li et al. 2015) and productivity (Locke 1981; Karakas and Tariq 1991; Zhang et al. 2012; Luo et al. 2015) of a well. For this reason, Abass and Bass (1988) studied the critical production rate in a water-coning system using numerical and physical models. Abass and Bass (1988) considered the radius of the cone, the maximum height of the water cone and the thickness of the oil zone as the control parameters for the calculation of the critical oil rate. Although their analysis was carried out for a restricted case which can only be approximated to the real conditions,

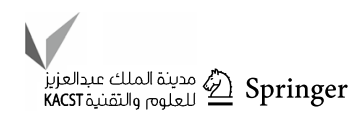


they concluded that the optimum perforation location is at the top of the formation whilst the length should be half of the oil zone thickness without considering the effect of perforation on skin effects. Pasztor and Toth (2017) investigated the effect of perforation parameters (shot density, perforation length, perforation radius and phase angle) on good productivity; however, they did not consider how these parameters could be used to determine the critical flow rate.
Three fundamental elements have been identified to form the basis for an optimized perforation strategy critical to maximizing hydrocarbon recovery. Firstly, perforations must be properly oriented via optimal perforation-gun orientation; second, debris from the perforation tunnels must be effectively removed via dynamic underbalanced perforating; and third, formation damage must be minimized through proper wellbore fluid selection during perforating (Behrmann et al.
Fig. 1 A perforated interval showing both the original reservoir static condition and water coning after the onset of production where $h$ is the oil column thickness, $h_{\mathrm{p}}$ is the well-perforated interval, WOC is water-oil contact, $D_{\mathrm{b}}$ is the distance from the bottom of the perforations to the original WOC, $\rho_{\mathrm{o}}$ is oil density and $\rho_{\mathrm{w}}$ is water density (Ahmed 2019)
Fig. 2 Perforation spacing and geometry (Bellarby 2009)
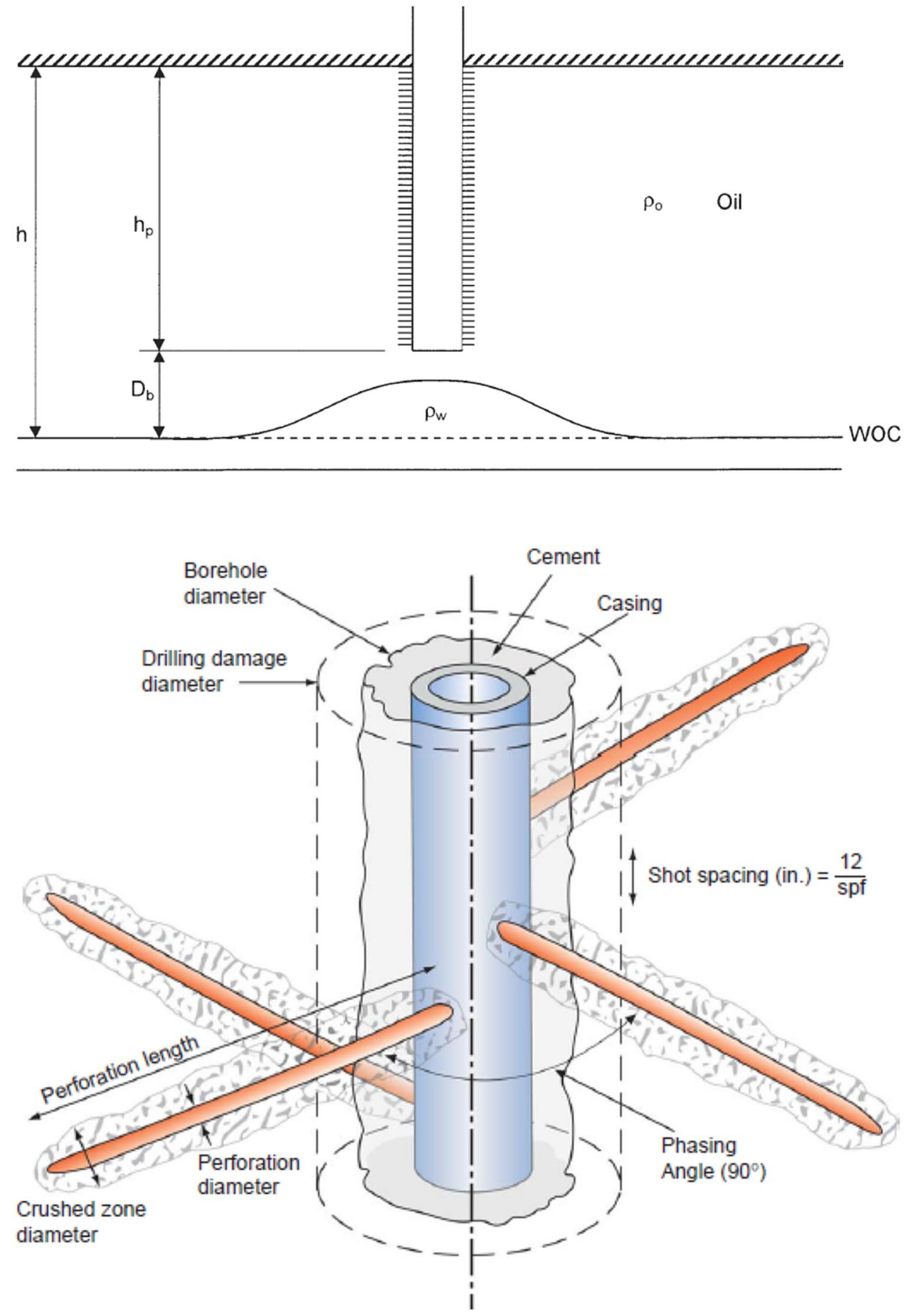


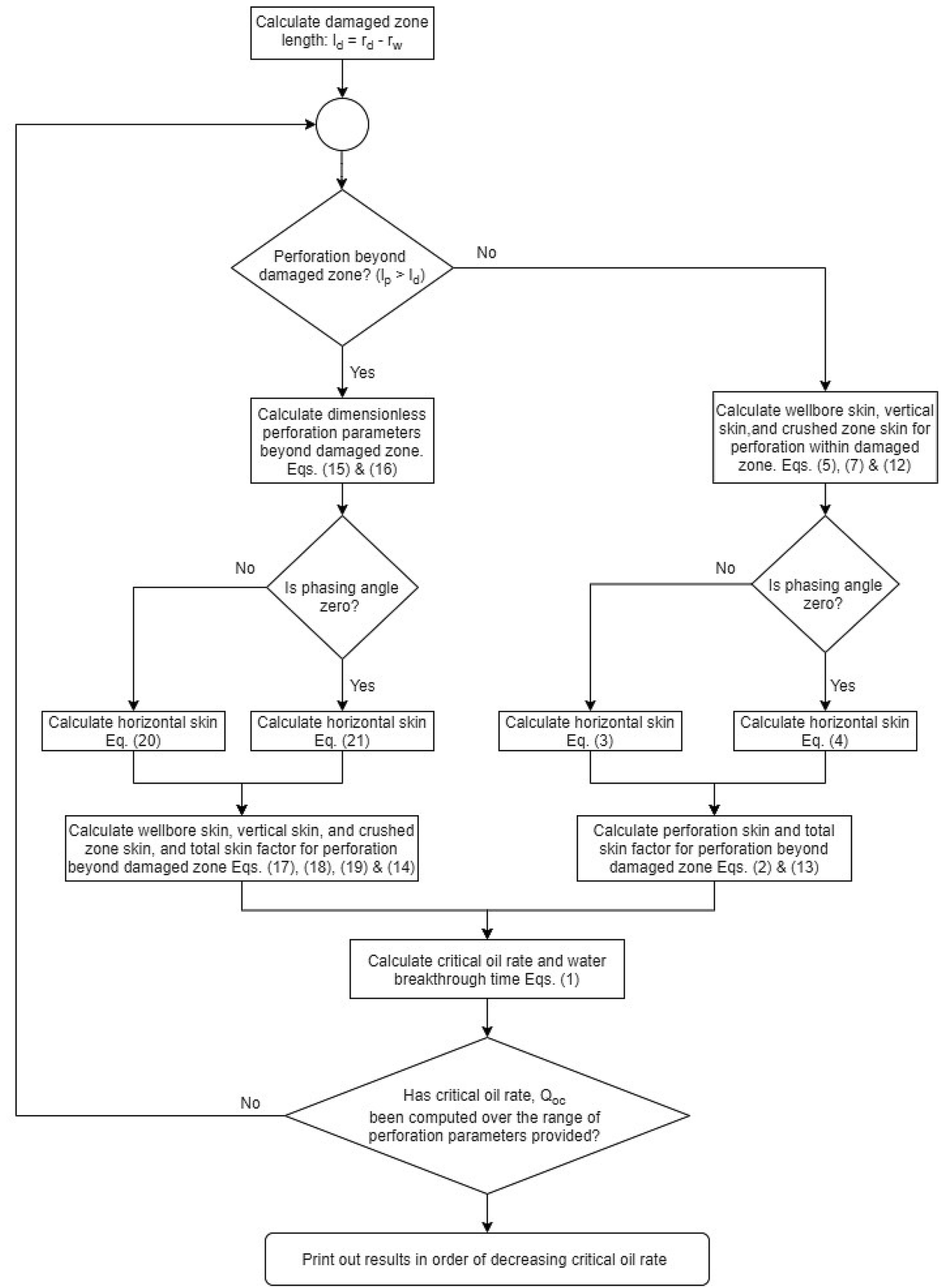

Fig. 3 Flow chart for model computation: It shows how to run sensitivity tests for optimal perforation parameters to obtain maximum water-free oil production rate 
Fig. 4 Perforation length of 6 in and spacing between perforations on critical flow rate at different phasing angles and perforation radius. i Spacing between perforations at 1 in, ii Spacing between perforations at $1.2 \mathrm{in,} \mathrm{iii} \mathrm{Spacing} \mathrm{between} \mathrm{perforations} \mathrm{at} 1.7$ in, iv Spacing between perforations at 2.4 in and $\mathbf{v}$ Spacing between perforations at 3 in

2007; Bellarby 2009; Onuh et al. 2019). In addition, perforation done closer to the water or gas layer has the possibility of producing water within a short time and thereby reducing hydrocarbon productivity.

In view of the fact that coning can have an important influence on operations, recovery and economics, it is of great value to optimize perforation length, position and interval to minimize both the skin factor and coning of water into the completion interval. This work investigates all the key perforation parameters as a function of the skin effect in critical flow rate determination. It also presents a workflow/ protocol to predict the maximum water-free oil production rate. The results obtained from a computational model developed to obtain the maximum water-free production rate in terms of perforation length, radius, spacing between perforations and phasing angle are presented in this paper. The mathematical details of the equations used and the presented results are in appendices.

\section{Theoretical basis}

Meyer and Garder (1954) developed a correlation for estimating the critical oil rate in the water coning system as shown schematically in Fig. 1.

A homogeneous system with a uniform permeability throughout the reservoir was assumed. The correlation shows that the critical oil rate is directly proportional to the difference between the water and oil densities, effective oil permeability and inversely proportional to oil viscosity (Eq. 1). If the total skin factor, $S_{\mathrm{dp}}$, is added to the equation then critical flow rate becomes

$Q_{\mathrm{oc}}=0.246 \times 10^{-4}\left[\frac{\rho_{\mathrm{w}}-\rho_{\mathrm{o}}}{\ln \left(r_{\mathrm{e}} / r_{\mathrm{w}}\right)+S_{\mathrm{dp}}}\right]\left(\frac{k_{\mathrm{o}}}{\mu_{\mathrm{o}} B_{\mathrm{o}}}\right)\left(h^{2}-h_{\mathrm{p}}^{2}\right)$

The skin factor as modelled by Karakas and Tariq (1991) captured perforation parameters and how they contribute to the skin damage (this is presented in "Appendix" section) and the critical flow rate. To determine either overall productivity and/or skin from the perforated interval, the performance of a single perforation must be considered. The overall perforation performance can then be evaluated by combining the phasing and shots per foot of multiple
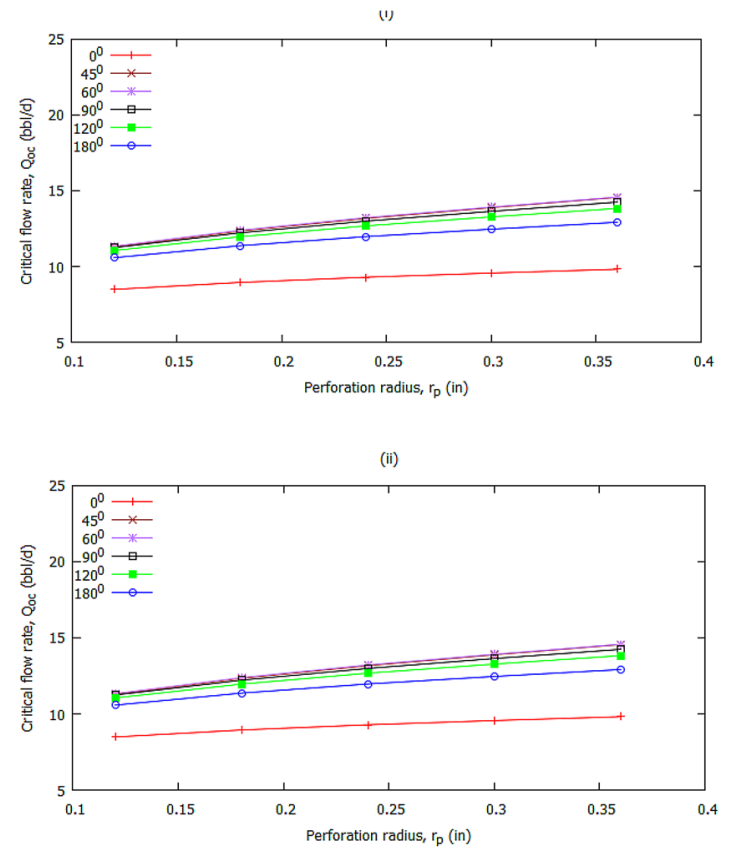

(iii)

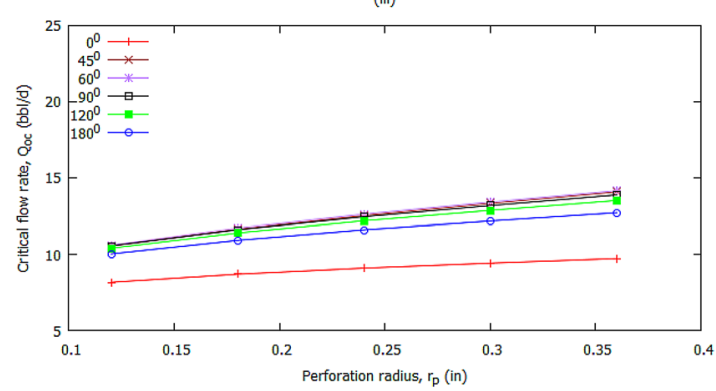

(iv)

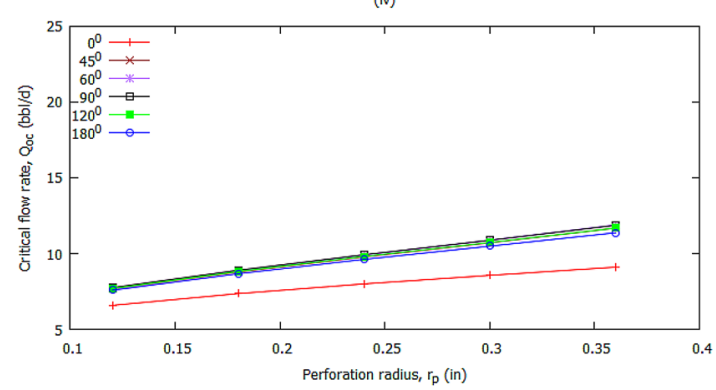

(v)

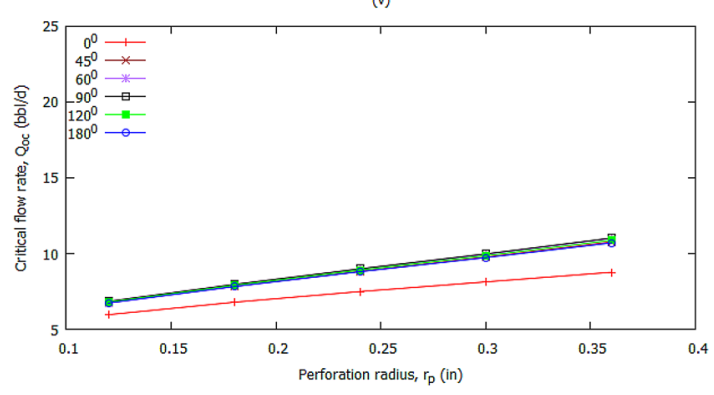


Fig. 5 Perforation length of 18 in and spacing between perforations on critical flow rate at different phasing angles and perforation radius. i Spacing between perforations at 1 in, ii Spacing between perforations at $1.2 \mathrm{in,} \mathrm{iii} \mathrm{Spacing} \mathrm{between} \mathrm{perforations} \mathrm{at} 1.7$ in, iv Spacing between perforations at 2.4 in and $\mathbf{v}$ Spacing between perforations at 3 in

adjacent perforations. A schematic of a perforated wellbore showing the altered near wellbore region is shown in Fig. 2.

\section{Computational model}

The Meyer and Garder critical coning correlation for the vertical well is employed in the computational model because it has been found to be the most conservative correlation from the literature (Joshi 1991; Ahmed 2019). Firstly, the computational model computes the overall skin from perforation within and beyond damage zones as a function of near wellbore parameters which include perforation length and radius, phasing angle and shot density. Secondly, the skin value obtained is incorporated into the maximum water-free oil production rate correlation. This implies that the optimum length, radius of perforation, phasing angle and shot density required to obtain maximum water-free oil production rate can be estimated prior to the drilling and perforating of the interval to be completed. The computational model flow sheet is presented in Fig. 3. The computational model was programmed in $\mathrm{C}++$.

The related well and reservoir data used for the computation are given in Table 3 in "Appendix"; however, for the purpose of analysis and discussion, few results were selected and plotted in Figs. 4, 5, 6, 7 and 8 at oil viscosity, $\mu_{\mathrm{o}}=0.73$ $\mathrm{cp}$; formation volume factor, $B_{\mathrm{o}}=1.0 \mathrm{bbl} / \mathrm{STB}$ and water density, $\rho_{\mathrm{w}}=63.76 \mathrm{lb} / \mathrm{ft}^{3}$.

For the effect of skin, we considered a vertical well drilled into an oil reservoir with perforation parameters of spacing between perforations, 2 in ( 6 shots/ft); perforation radius, $r_{\mathrm{p}}=0.16$ in; phasing $=45$ degrees; oil viscosity, $\mu_{\mathrm{o}}=1 \mathrm{cp}$; formation volume factor, $B_{\mathrm{o}}=1.1 \mathrm{bbl} / \mathrm{STB}$ and water density, $\rho_{\mathrm{w}}=62.4 \mathrm{lb} / \mathrm{ft}^{3}$. Considering the perforations that terminate within and beyond the damaged zones, the overall skin factor varies with perforation length as shown in Table 1.

There was a large skin factor when the perforation was done within the damaged zone; however, when the perforation length was increased by 2 in, a drastic reduction of 6.2 from skin factor was recorded. As perforation length was increased further and crossed a little bit beyond damaged zone, there was a further reduction of 0.9 in skin factor. Generally, the combined effect of perforation done beyond the damaged zone and increase in perforation length was evident as the overall skin decreases with

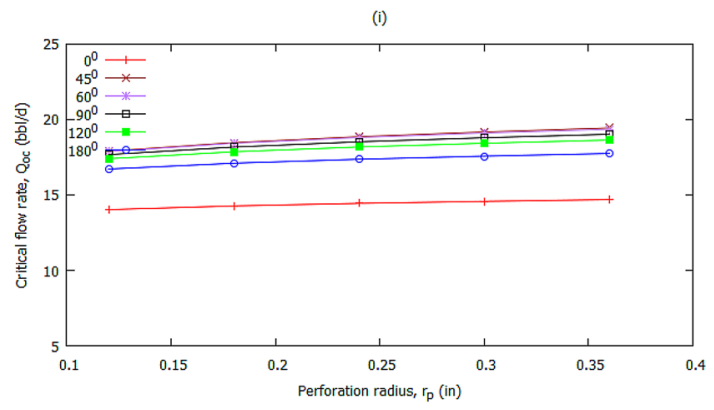

(ii)

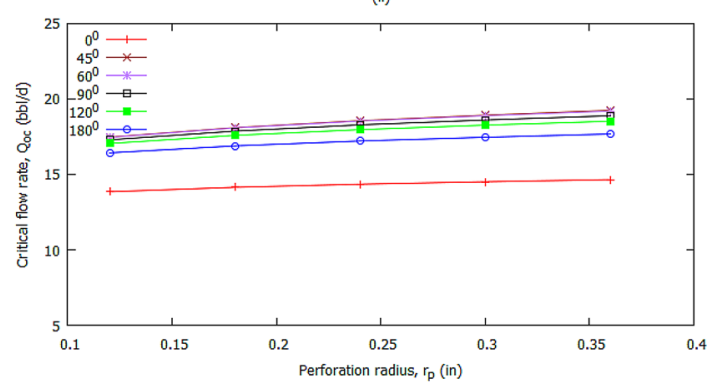

(iii)

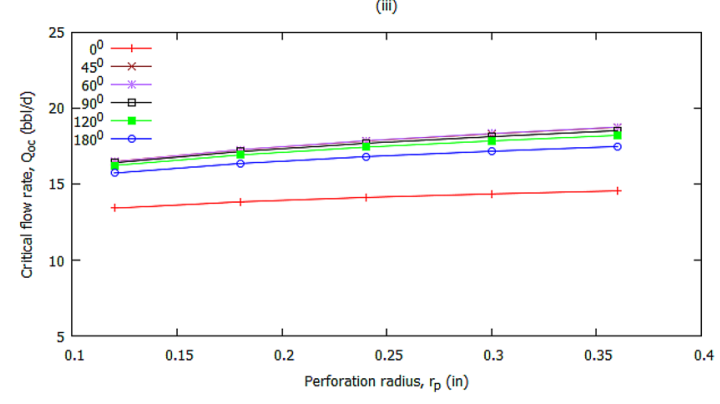

(iv)

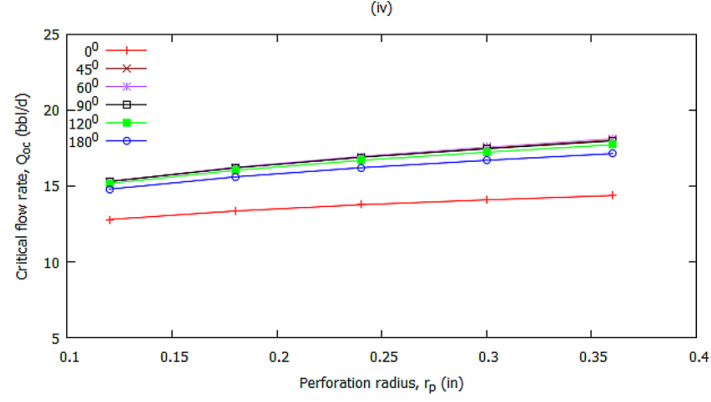

(v)

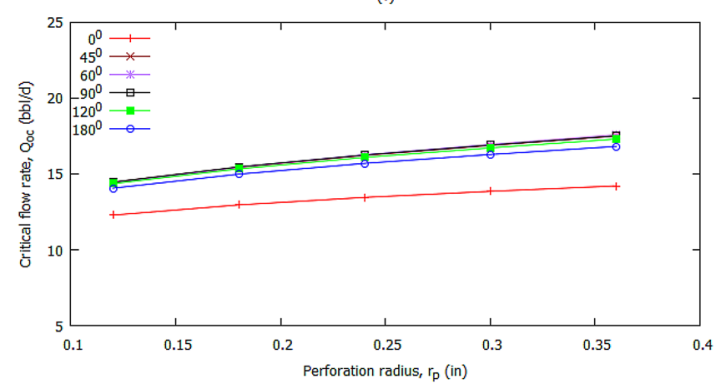


Fig. 6 Perforation length of 30 in and spacing between perforations on critical flow rate at different phasing angles and perforation radius. i Spacing between perforations at 1 in, ii Spacing between perforations at $1.2 \mathrm{in,} \mathrm{iii} \mathrm{Spacing} \mathrm{between} \mathrm{perforations} \mathrm{at} 1.7$ in, iv Spacing between perforations at 2.4 in and $\mathbf{v}$ Spacing between perforations at 3 in

increasing perforation length. Hence, the effect of phasing, perforation radius and other perforation parameters on overall skin can be evaluated prior to drilling and completion operations. The optimal combination of perforation parameters that minimizes skin can be obtained from the computational model.

Using the modified Mayer and Garder correlation (Eq. 1), the influence of skin factor on the maximum water-free oil production rate is shown in Table 1. The loss in productivity due to overall skin is evident in Table 1. This demonstrates how perforation parameters can add to the effect of skin factors on flow rate. Thus, the completion operation could be carried out with optimal perforation length as well as other perforation parameters to minimize the skin and maximize the water-free oil production rate.

\section{Results and discussion}

\section{Effect of phasing angles}

Critical rate increases with phasing angle in the order of $0^{\circ}, 180^{\circ}, 90^{\circ}, 120^{\circ}, 45^{\circ}$ and $60^{\circ}$ for a perforation length of 6 in and for the spacing between perforation of 1 to 3 in (Fig. 4). The same pattern was recorded for a perforation length of 18 in and 30 in but for the spacing between perforation above 1.2 in and above 2.4 in, respectively (Figs. 5, 6). It was observed that both the spacing between perforations and perforation length have influence on the phasing angle yielding an optimum critical rate between $45^{\circ}$ and $60^{\circ}$. Hence, the above phasing angle order changed to $0^{\circ}$, $180^{\circ}, 90^{\circ}, 120^{\circ}, 60^{\circ}$ and $45^{\circ}$ from perforation length of 18 in except for perforation length in favour of $60^{\circ}$ (Figs. 5, 6, $7,8)$. Hence, the only condition that will make a $60^{\circ}$ phasing angle a better option is when the perforation length is shorter with wider perforation spacing.

\section{Effect of spacing between perforations}

The impact of a decrease in spacing between perforations (which is an increase in perforation density) on the critical flow rate is small. For instance, from Fig. 6 at a perforation length of 30 in, perforation radius of 0.36 in and at a phasing angle of $45^{\circ}$, the critical rate recorded is $21.29 \mathrm{bbl} /$ day, 21 . $16 \mathrm{bbl} /$ day, $20.80 \mathrm{bbl} /$ day, $20.29 \mathrm{bbl} /$ day and $19.87 \mathrm{bbl} /$ day at spacing between perforation of 1 in, 1.2 in, $1.7 \mathrm{in,} 2.4$,
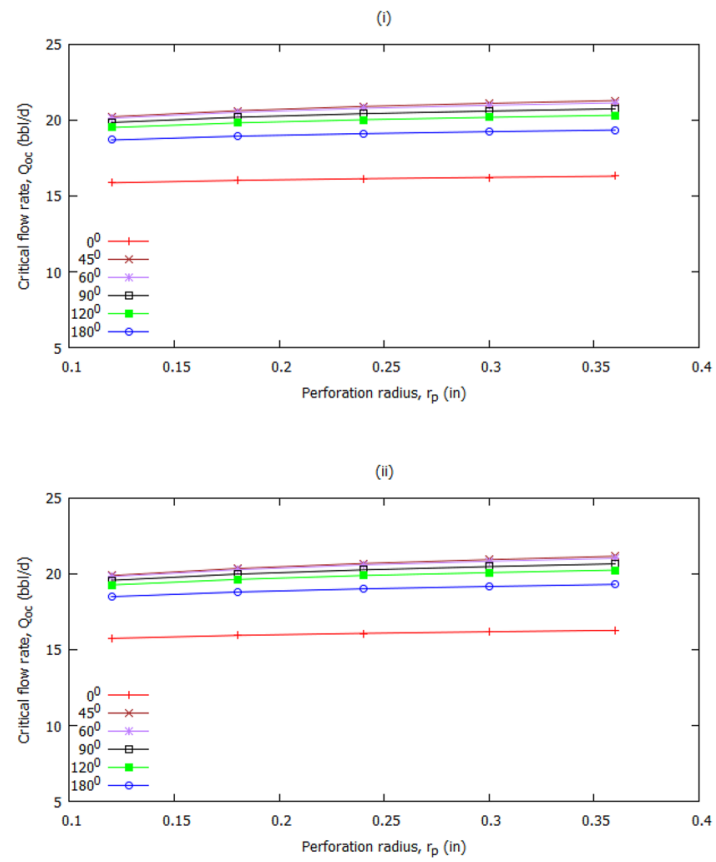

(iii)

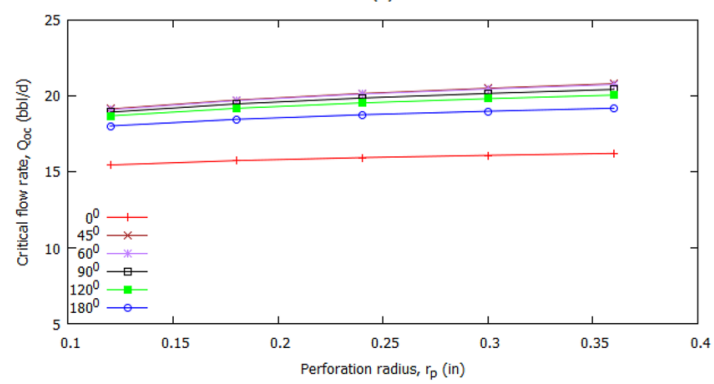

(iv)

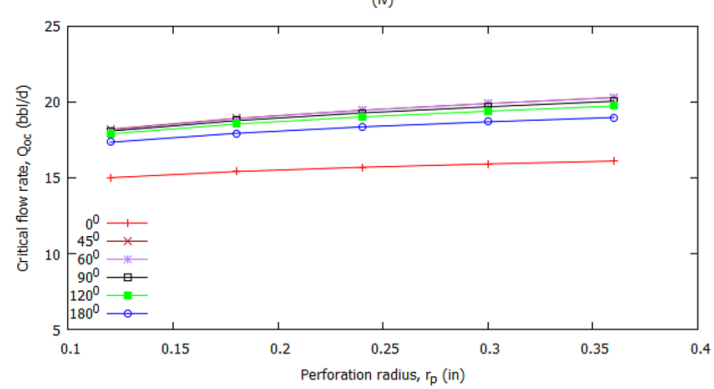

(v)

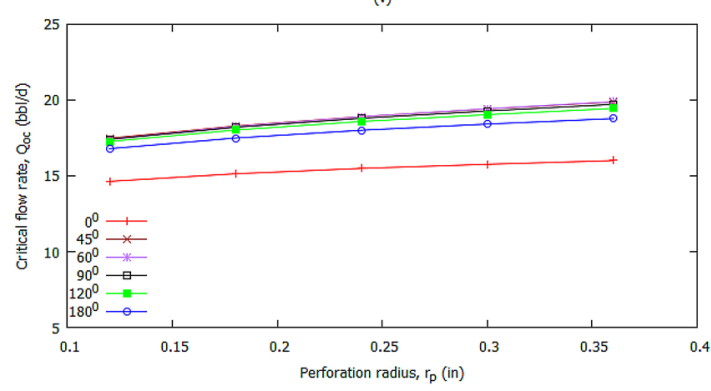


Fig. 7 Perforation length of 42 in and spacing between perforations on critical flow rate at different phasing angles and perforation radius. i Spacing between perforations at 1 in, ii Spacing between perforations at 1.2 in, iii Spacing between perforations at 1.7 in, iv Spacing between perforations at 2.4 in and (v) Spacing between perforations at 3 in

and 3 in respectively. There was just $1.42 \mathrm{bbl} /$ day of oil that will be added for decreasing the spacing between perforations from 3 to 1 in. Hence, the need to consider the cost of perforation to determine optimal perforation density to aid cost-effective completion.

\section{Effect of perforation radius}

Increasing the perforation radius from 0.12 in to 0.36 in has a minimum and maximum increment on critical flow rate to be $0.3 \mathrm{bbl} /$ day and $4.25 \mathrm{bbl} /$ day. These minimum and maximum are recorded at a perforation length of $48 \mathrm{in}$, the spacing between perforations of 1 in and a phasing angle of $0^{\circ}$ and the maximum effect at a perforation length of 6 in, the spacing between perforations of 3 in and a phasing angle of $60^{\circ}$, respectively. However, as the perforation length increases the effect of perforation radius reduces as the gradient reduces/flattens out (Figs. 4, 5, 6, 7, 8). It implies that the effect of an increase in perforation length overshadows the effect of an increase in perforation radius. For example, at perforation length of 6 in, the spacing between perforations of 1 in and at phasing angle of $180^{\circ}$ there is an increment of $2.33 \mathrm{bbl} /$ day critical flow rate by increasing the perforation radius from 0.12 in to 0.36 in whilst the increment has reduced to $0.45 \mathrm{bbl} /$ day at perforation length of 48 in (Figs. 4i and 8i). Similarly, the increment reduces from $3.97 \mathrm{bbl} /$ day to $1.48 \mathrm{bbl} /$ day when the perforation length was increased from 6 to 48 in at spacing between perforations of 3 in and at a phasing angle of $180^{\circ}$ (Figs. $4 \mathrm{v}$ and $8 \mathrm{v}$ ).

\section{Effect of perforation length}

An increase in perforation length increases the critical flow rate, however, the effect reduces drastically as the perforation length reached 30 in (Figs. 4, 5, 6, 7, 8). For instance, Figs. $4 \mathrm{i}$ to $8 \mathrm{i}$ show that at a phasing angle of $120^{\circ}$, the spacing between perforations of 1 in and perforation length of $6 \mathrm{in,} 18 \mathrm{in}, 30 \mathrm{in}, 42$ in and 48 there are critical flow rate increment percentage of $35 \%, 9.1 \%, 5.95 \%$ and $2.4 \%$. Also, Figs. $4 \mathrm{v}$ to $8 \mathrm{v}$ show that at phasing angle of $120^{\circ}$ but the spacing between perforations of 3 in and perforation length of $6 \mathrm{in}, 18 \mathrm{in}, 30 \mathrm{in}, 42 \mathrm{in}$ and 48 there is a critical flow rate increment percentage of $59 \%, 12.4 \%, 7.3 \%$ and $2.8 \%$.

Similar observations were made by Pasztor and Toth (2017), when the authors investigated sensitivity tests of perforation parameters on the production rate.
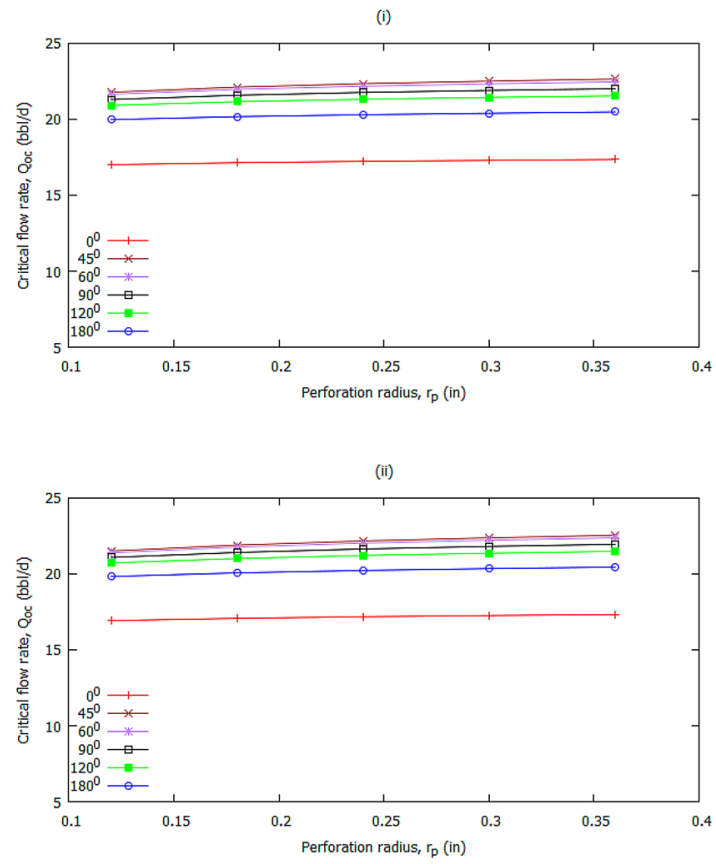

(iii)

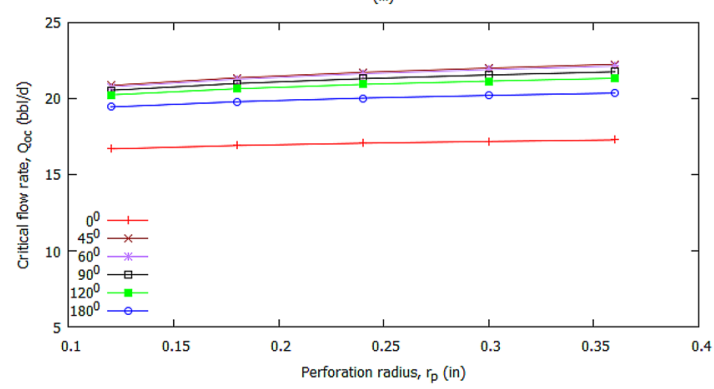

(iv)

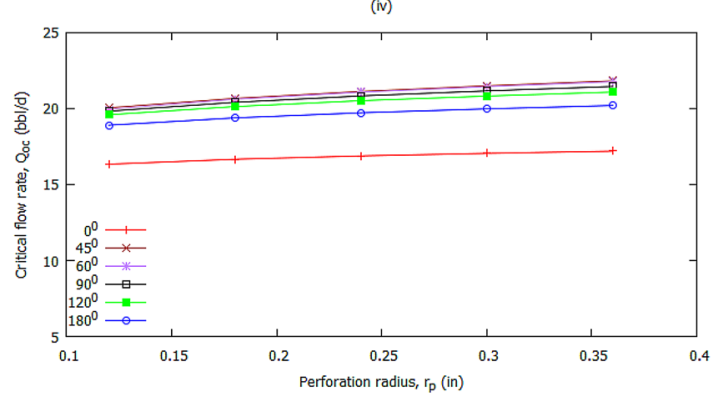

(v)

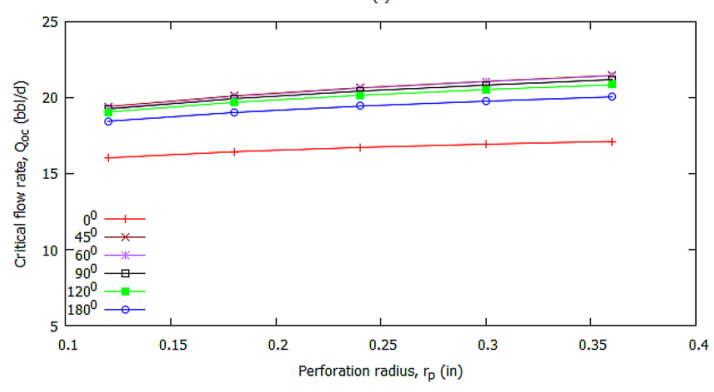


Fig. 8 Perforation length of 48 in and spacing between perforations on critical flow rate at different phasing angles and perforation radius. i Spacing between perforations at 1 in, ii Spacing between perforations at $1.2 \mathrm{in,} \mathrm{iii} \mathrm{Spacing} \mathrm{between} \mathrm{perforations} \mathrm{at} 1.7$ in, iv Spacing between perforations at 2.4 in and $\mathbf{v}$ Spacing between perforations at 3 in

\section{Conclusion}

A computation model that predicts the maximum waterfree oil production rate has been presented. This model incorporates the skin factor as a function of the perforation parameters. The model will aid engineers in obtaining the optimal combination of perforation parameters that minimize the total skin factor. The critical flow rate generally increases with an increase in perforation radius for all phasing angles considered, although the gradient reduces/ flatten out as the perforation length increases. The effect of perforation radius reduces with an increase in the perforation length. The model shows that the optimal perforation angles are $45^{\circ}$ and $60^{\circ}$ with a marginal difference in rates, and $0^{\circ}$ is the worst perforation angle. Considering the input data used for the computation in this work, the perforation parameters that produced maximum water-free oil rate of $23.2 \mathrm{std} / \mathrm{d}$ are $45^{\circ}, 1 \mathrm{in}, 0.36$ in and 48 in of phasing angle, spacing between perforation, perforation radius and perforation length, respectively.

Funding This research received no specific grant from any funding agency in the public, commercial, or not-for-profit sectors.

Open Access This article is licensed under a Creative Commons Attribution 4.0 International License, which permits use, sharing, adaptation, distribution and reproduction in any medium or format, as long as you give appropriate credit to the original author(s) and the source, provide a link to the Creative Commons licence, and indicate if changes were made. The images or other third party material in this article are included in the article's Creative Commons licence, unless indicated otherwise in a credit line to the material. If material is not included in the article's Creative Commons licence and your intended use is not permitted by statutory regulation or exceeds the permitted use, you will need to obtain permission directly from the copyright holder. To view a copy of this licence, visit http://creativecommons.org/licenses/by/4.0/.

\section{Appendix: Perforation skin $\left(S_{p}\right)$}

A semi-analytical perforation skin model for calculating the overall skin due to drilling damage and perforation is expressed as Eq. 3 (Karakas and Tariq 1991). The perforation skin $\left(S_{\mathrm{p}}\right)$ excluding the drilling damage skin is the sum of the horizontal skin $\left(S_{\mathrm{h}}\right)$, wellbore skin $\left(S_{\mathrm{wb}}\right)$, vertical skin $\left(S_{\mathrm{v}}\right)$ and the crushed zone skin $\left(S_{\mathrm{c}}\right)$ :

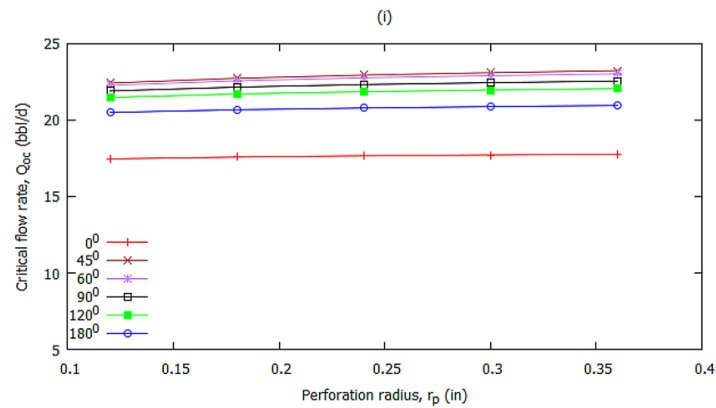

(ii)

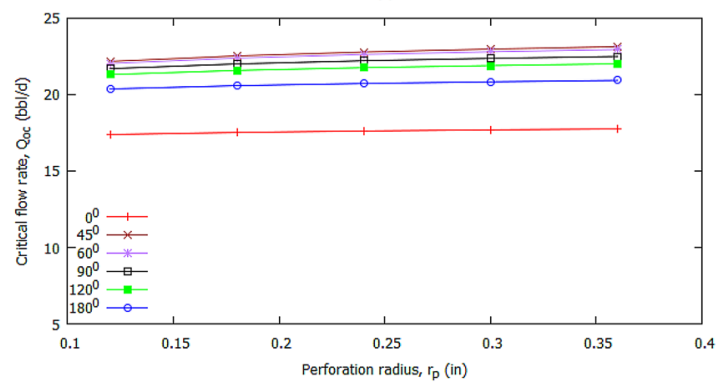

(iii)

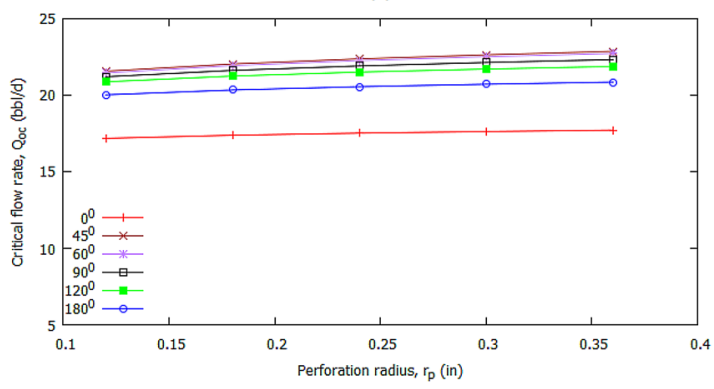

(iv)

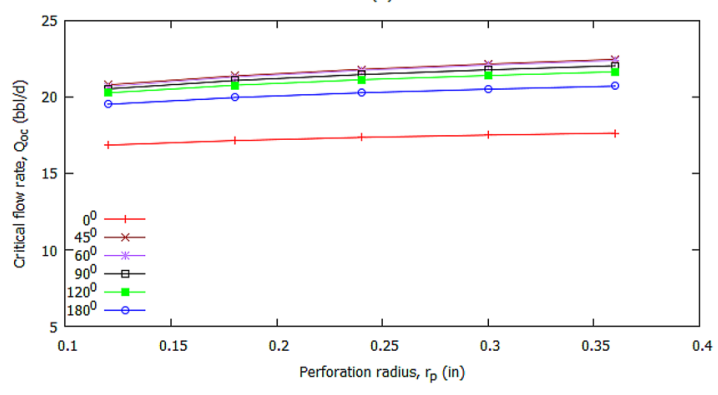

(v)

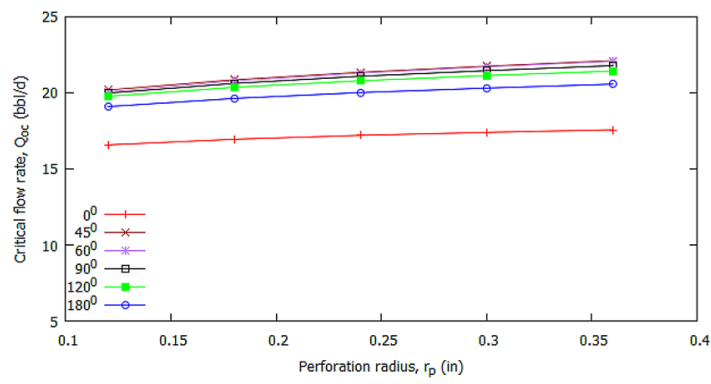


Table 1 Overall skin to perforation length test at perforation done within and beyond damaged zones

\begin{tabular}{|c|c|c|c|c|}
\hline \multirow[b]{2}{*}{$\begin{array}{l}\text { Perfo- } \\
\text { ration } \\
\text { length, in }\end{array}$} & \multicolumn{2}{|c|}{$\begin{array}{l}\text { Perforation within dam- } \\
\text { aged zone }\end{array}$} & \multicolumn{2}{|c|}{$\begin{array}{l}\text { Perforation beyond damaged } \\
\text { zone }\end{array}$} \\
\hline & Skin & $\begin{array}{l}\text { Maximum water- } \\
\text { free oil production } \\
\text { rate, std/d }\end{array}$ & Skin & $\begin{array}{l}\text { Maximum water-free } \\
\text { oil production rate, } \\
\text { std/d }\end{array}$ \\
\hline 6 & 9.5 & 4.29 & - & - \\
\hline 8 & 3.3 & 6.67 & - & - \\
\hline 10 & - & - & 2.4 & 7.3 \\
\hline 12 & - & - & 1.5 & 7.9 \\
\hline 18 & - & - & -0.19 & 9.7 \\
\hline 30 & - & - & -1.9 & 12.6 \\
\hline
\end{tabular}

$S_{\mathrm{p}}=S_{\mathrm{h}}+S_{\mathrm{wb}}+S_{\mathrm{v}}+S_{\mathrm{c}}$

where

$S_{\mathrm{h}}=\ln \left(\frac{r_{\mathrm{w}}}{\alpha\left(r_{\mathrm{w}}+l_{\mathrm{p}}\right)}\right)$ for phasing angles other than $0^{0}$

$S_{\mathrm{h}}=\ln \left(\frac{4 r_{\mathrm{w}}}{l_{\mathrm{p}}}\right) \quad$ for the case of $0^{0}$ phasing

$S_{\mathrm{wb}}=C_{1} \exp \left(C_{2} r_{\mathrm{wD}}\right)$

$r_{\mathrm{wD}}=\frac{r_{\mathrm{w}}}{l_{\mathrm{p}}+r_{\mathrm{w}}} \quad$ dimensionless well bore radius

$S_{\mathrm{v}}=10^{a} h_{\mathrm{D}}^{b-1} r_{\mathrm{pD}}^{b}$

$h_{\mathrm{D}}=\frac{h_{\mathrm{s}}}{l_{\mathrm{p}}} \sqrt{\frac{k_{\mathrm{h}}}{k_{\mathrm{v}}}}$ dimensionless spacing between perforations

$r_{\mathrm{pD}}=\frac{r_{\mathrm{p}}}{2 h_{\mathrm{s}}}\left(1+\sqrt{\frac{k_{\mathrm{h}}}{k_{\mathrm{v}}}}\right)$ dimensionless perforation radius $a=a_{1} \log _{10}\left(r_{p D}\right)+a_{2}$

$b=b_{1} r_{\mathrm{pD}}+b_{2}$

$S_{\mathrm{c}}=\frac{h_{\mathrm{s}}}{l_{\mathrm{p}}}\left(\frac{k}{k_{\mathrm{c}}}-1\right) \ln \left(\frac{r_{\mathrm{c}}}{r_{\mathrm{p}}}\right)$.

The constants $\alpha, \alpha_{1}, \alpha_{2}, b_{1}, b_{2}, C_{1}, C_{2}$, are obtainable based on gun-phasing angle in Table 2.

The calculation of overall skin varies depending on whether or not the perforation terminates within the drilling damaged zone. For perforations terminating within the damaged zone (i.e. $l_{\mathrm{p}}<l_{\mathrm{d}}$ ) the calculation of the overall skin which is the combination of drilling damage and perforation $\left(S_{\mathrm{dp}}\right)$ is given as follows:

$S_{\mathrm{dp}}=\left(\frac{k}{k_{\mathrm{d}}}-1\right) \ln \left(\frac{r_{\mathrm{d}}}{r_{\mathrm{w}}}\right)+\left(\frac{k}{k_{\mathrm{d}}}\right)\left(S_{\mathrm{p}}+S_{\aleph}\right)$

The parameter $S_{\aleph}$ is used for boundary effect correction and is often ignored. Computation of the overall skin in this paper is based on data in Table 3.

The overall skin $\left(S_{\mathrm{dp}}\right)$ for the more relevant case of perforations that extend beyond the damage zone is expressed as follows:

$S_{\mathrm{dp}}=S_{\mathrm{h}}^{\prime}+S_{\mathrm{wb}}^{\prime}+S_{\mathrm{v}}^{\prime}+S_{\mathrm{c}}^{\prime}$

Meanwhile, the perforation length and wellbore radius are modified as follows:

$l_{\mathrm{p}}^{\prime}=l_{\mathrm{p}}-\left(1-\frac{k_{\mathrm{d}}}{k}\right) l_{\mathrm{d}}$

$r_{\mathrm{w}}^{\prime}=r_{\mathrm{w}}+\left(1-\frac{k_{\mathrm{d}}}{k}\right) l_{\mathrm{d}}$

$l_{\mathrm{p}}^{\prime}$ and $r_{\mathrm{w}}^{\prime}$ are used instead of $l_{\mathrm{p}}$ and $r_{\mathrm{w}}$ in Eqs. (6) and (9). The modified perforation length and wellbore radius also affect $S_{\mathrm{wb}}, S_{\mathrm{v}}$, and $S_{\mathrm{c}}$ to become modified $\left(S_{\mathrm{wb}}^{\prime}, S_{\mathrm{v}}^{\prime}, S_{\mathrm{c}}^{\prime}\right)$ thus:

$S_{\mathrm{wb}}^{\prime}=C_{1} \exp \left(C_{2} r_{\mathrm{wD}}^{\prime}\right)$
Table 2 Gun-phasing parameters for Karakas and Tariq perforation model (Bellarby 2009)

\begin{tabular}{llllllll}
\hline Phasing $\left(^{\circ}\right)$ & $\alpha \times 10^{-2}$ & $C_{1} \times 10^{-5}$ & $C_{2} \times 10^{-3}$ & $a_{1} \times-10^{-3}$ & $a_{2} \times 10^{-4}$ & $b_{1} \times 10^{-4}$ & $b_{2} \times 10^{-4}$ \\
\hline 0 & N/A & 0.000016 & 2675 & 2091 & 453 & 51,313 & 18,672 \\
180 & 50 & 0.0026 & 4532 & 2025 & 943 & 30,373 & 18,115 \\
120 & 64.8 & 0.066 & 5320 & 2018 & 634 & 16,136 & 17,770 \\
90 & 72.6 & 0.019 & 6155 & 1905 & 1038 & 1.5674 & 16,935 \\
60 & 81.3 & 0.3 & 7509 & 1898 & 1023 & 13,654 & 16,490 \\
45 & 86 & 4.6 & 8791 & 1788 & 2398 & 11,915 & 16,392 \\
\hline
\end{tabular}


Table 3 Input reservoir data, well, fluids and perforation data
Parameter
Symbol/
Data
nomenclature

\begin{tabular}{|c|c|c|c|}
\hline 1 & Wellbore radius, $\mathrm{ft}$ & $r_{\mathrm{w}}$ & 0.25 \\
\hline 2 & Drainage radius, $\mathrm{ft}$ & $r_{\mathrm{e}}$ & 660 \\
\hline 3 & Damaged zone radius, $\mathrm{ft}$ & $r_{\mathrm{d}}$ & 0.96 \\
\hline 4 & Crushed zone radius around perforation, $\mathrm{ft}$ & $r_{\mathrm{c}}$ & 0.042 \\
\hline 5 & Permeability, md & $K$ & 110 \\
\hline 6 & Crushed zone permeability, md & $k_{\mathrm{c}}$ & 20 \\
\hline 7 & Damaged zone permeability, md & $k_{\mathrm{d}}$ & 50 \\
\hline 8 & Vertical permeability, md & $k_{\mathrm{v}}$ & 110 \\
\hline 9 & Horizontal permeability, md & $k_{\mathrm{h}}$ & 110 \\
\hline 10 & Area, acre & $A$ & 31.41 \\
\hline 11 & Porosity, $\%$ & phi & 20 \\
\hline 12 & Total compressibility, 1/psi & $C_{\mathrm{t}}$ & 0.000015 \\
\hline 13 & Oil column thickness, $\mathrm{ft}$ & $h$ & 50 \\
\hline 14 & Water viscosity, $\mathrm{cp}$ & $\mu_{\mathrm{w}}$ & 0.5 \\
\hline 15 & Water relative permeability at residual oil saturation & $k_{\mathrm{rw} \_} S_{\text {or }}$ & 0.45 \\
\hline 16 & Oil relative permeability at connate water saturation & $k_{\mathrm{ro} \_} S_{\mathrm{wc}}$ & 0.8 \\
\hline 17 & Oil density, $\mathrm{lb} / \mathrm{ft}^{3}$ & $\rho_{\mathrm{o}}$ & 47 \\
\hline 18 & Oil viscosity, cp & $\mu_{\mathrm{o}}$ & 0.73 to 1 \\
\hline 19 & Water density, $\mathrm{lb} / \mathrm{ft}^{3}$ & $\rho_{\mathrm{w}}$ & 62.4 and 63.76 \\
\hline 20 & Formation volume factor, $B_{\mathrm{o}}$ & $\mathrm{bbl} / \mathrm{STB}$ & 1 to 1.1 \\
\hline 21 & Perforation length, in & $l_{\mathrm{p}}$ & $6,18,30,42,48$ \\
\hline 22 & Perforation radius, in & $r_{\mathrm{p}}$ & 0.36 to 0.12 \\
\hline 23 & Effective oil permeability, md & $k_{\mathrm{o}}$ & 95 \\
\hline 24 & Perforated interval, $\mathrm{ft}$ & $h_{\mathrm{p}}$ & 15 \\
\hline 25 & Spacing between perforations, in & $h_{\mathrm{s}}$ & 1 to 3 \\
\hline 26 & Phasing, degree & & $0,180,120,90,60$ and 45 \\
\hline 27 & $\begin{array}{l}\text { Distance from the bottom of the perforations to the } \\
\text { original water-oil contact, } \mathrm{ft}\end{array}$ & $D_{\mathrm{b}}$ & 35 \\
\hline
\end{tabular}

$S_{\mathrm{v}}^{\prime}=10^{a}\left(h_{\mathrm{D}}^{\prime}\right)^{b-1} r_{\mathrm{pD}}^{b}$

$S_{\mathrm{c}}^{\prime}=\frac{h_{\mathrm{s}}}{l_{\mathrm{p}}^{\prime}}\left(\frac{k}{k_{\mathrm{c}}}-1\right) \ln \left(\frac{r_{\mathrm{c}}}{r_{\mathrm{p}}}\right)$

Meanwhile, $S_{\mathrm{h}}$ is partly calculated using $r_{\mathrm{w}}$, such that $S_{\mathrm{h}}^{\prime}$ is given by

$S_{\mathrm{h}}^{\prime}=\ln \left(\frac{r_{\mathrm{w}}}{\alpha\left(r_{\mathrm{w}}^{\prime}+l_{\mathrm{p}}^{\prime}\right)}\right)$ for phasing angles other than $0^{0}$

$S_{\mathrm{h}}^{\prime}=\ln \left(\frac{4 r_{\mathrm{w}}}{l_{\mathrm{p}}^{\prime}}\right)$ for the case of $0^{0}$ phasing

\section{References}

Abass HH, Bass DM (1988) The critical production rate in waterconing system. Society of Petroleum Engineers. https://doi. org/10.2118/17311-MS

Ahmed T (2019) Gas and Water Coning. In: Ahmed T (ed) Reservoir engineering handbook, 3 and 5th edn. Gulf Professional Publishing, pp. 605-661. https://doi.org/10.1016/B978-0-12-81364 9-2.00009-8.

Behrmann L, Walton IC, Chang FF, Fayard A, Khong CK, Langseth B, Mason S, Mathisen A, Pizzolante I, Xiang T, Svanes G (2007) Optimal fluid systems for perforating. Oilfield Rev 19:14-25

Bellarby J (2009) Well completion design. Elsevier Science, Amsterdam

Chierici GL, Ciucci GM, Pizzi G (1964) A systematic study of gas and water coning by potentiometric models. J Pet Technol 16:923929. https://doi.org/10.2118/871-PA

Høyland LA, Papatzacos P, Skjaeveland SM (1989) Critical rate for water coning: correlation and analytical solution. Society of Petroleum Engineers, London. https://doi.org/10.2118/15855-PA

Joshi S (1991) Horizontal well technology. Pennwell Publishing Company, Tulsa 
Karakas M, Tariq SM (1991) Semianalytical productivity models for perforated completions. Society of Petroleum Engineers, London. https://doi.org/10.2118/18247-PA

Locke S (1981) An advanced method for predicting the productivity ratio of a perforated well. Society of Petroleum Engineers, London. https://doi.org/10.2118/8804-PA

Li Y, Li H, Li Y (2015) Prediction method of bottom water coning profile and water breakthrough time in bottom water reservoir without barrier. Math Prob Eng. https://doi.org/10.1155/2015/149490

Luo X, Jiang L, Su Y, Huang K (2015) The productivity calculation model of perforated horizontal well and optimization of inflow profile. Petroleum 1:154-157. https://doi.org/10.1016/j.petlm 2015.04.002

Menouar HK, Hakim AA (1995) Water coning and critical rates in vertical and horizontal wells. Society of Petroleum Engineers, London. https://doi.org/10.2118/29877-MS

Meyer HI, Garder AO (1954) mechanics of two immiscible fluids in porous media. J Appl Phys 25:1400-1406. https://doi. org/10.1063/1.1721576

Onuh CY, Ogunkunle TF, Oluwatosin JR, Efeoghene E (2019) The impact of perforation geometry on oil well productivity. IJMET 10:1012-1021

Papatzacos P, Herring TR, Martinsen R, Skjaeveland SM (1989) Cone breakthrough time for horizontal wells. Society of Petroleum Engineers, London. https://doi.org/10.2118/19822-PA
Pasztor AV, Toth A (2017) Effect of perforation parameters on the productivity of geothermal wells. In: The publications of the multiscience-XXXI. MicroCAD international scientific conference. https://doi.org/10.26649/musci.2017.002

Tabatabaei M, Ghalambor A, Guo B (2012) An analytical solution for water coning in vertical wells. Society of Petroleum Engineers, London. https://doi.org/10.2118/113106-PA

Yang W, Wattenbarger RA (1991) Water coning calculations for vertical and horizontal wells. Society of Petroleum Engineers, London. https://doi.org/10.2118/22931-MS

Zhang L, Zhao Y, Liu Z (2011) A novel steady-state productivity equation for horizontal wells in bottom water drive gas reservoirs. Petrol Sci 8:63-69. https://doi.org/10.1007/s12182-011-0116-2

Zhang HJ, Yang ZZ, Guan PJ, Xu GP, Fu L, Li HY, Xu L (2012) Sectional optimization study on perforation parameters of horizontal wells in Daqing oilfield. Adv Mater Res 594-597:2586-2589. https://doi.org/10.4028/www.scientific.net/amr.594-597.2586

Publisher's Note Springer Nature remains neutral with regard to jurisdictional claims in published maps and institutional affiliations. 